\title{
Analysis of Clearance Volume's Influence on Expansion Process of Reciprocating Compressor based on Matlab/Simulink
}

\author{
Jixiang Wang ${ }^{1,}$, , Yongsheng $\mathrm{Su}^{2, \mathrm{~b}}$ \\ ${ }^{1}$ School of Mechanical and Power Engineering, East China University of Science and Technology, \\ Shanghai 200000, China; \\ ${ }^{2}$ School of Mechanical and Power Engineering, East China University of Science and Technology, \\ Shanghai 200000, China. \\ awangjixiang08@126.com, byssu@ecust.edu.cn.
}

Keywords: reciprocating compressor, expansion model, simulink, design tool.

\begin{abstract}
Mathematical model and boundary conditions of expansion process are established. The method of modeling expansion process with Simulink and its simulation is discussed. By using IIZA-1.5/8compressor as research subject, the models with an easily operable interface is built and extract the clearance volume's influence on expansion ending angle, pressure and temperature in expansion process by using the operable model. In this sense, this operable model can serve as an design and refine model of compressor for its visibility and easy revising property.
\end{abstract}

\section{Introduction}

In case of cylinder parts impacting and over-wearing, reciprocating compressor has clearance volume with gas in it. After expansion process, gas in this place expands and influence later process, hence study and analysis about expansion process is essential.

Simulink is comprehensive software package which can describe and analyze a dynamic system with its simple block[1]. After the model being packaged, the model has good visibility and can extract the influence of chosen parameter on the expansion process. Based on this, the method of describing expansion with differential equation and of analyzing it with Simulink is discussed.

\section{Differential Equation Description of the Simulink Model}

Differential Equation of Expansion Process. Pressure ration of this compressor is not big, it can be assumed that: cylinder has no leakage; the gas in cylinder is ideal gas. The relation equation between gas temperature and crank angle is:

$$
\frac{\mathrm{dT}}{\mathrm{d} \theta}=\frac{1}{\mathrm{~m}_{\mathrm{c}} \mathrm{C}_{\mathrm{v}}}\left(\frac{\mathrm{dQ}}{\mathrm{d} \theta}-\mathrm{p} \frac{\mathrm{dV}}{\mathrm{d} \theta}\right)
$$

$\theta$-crank angle ; $d Q$ - heat transfer from wall to gas; $m_{c}$ - gas mass left in clearancevolume; Pressure change in cylinder is :

$$
\mathrm{p}=\frac{\mathrm{m}_{\mathrm{c}} \mathrm{R}_{\mathrm{g}} \mathrm{T}}{\mathrm{V}_{\mathrm{c}}}
$$

Differential equation is solved by simulink ode45 algorithm.According to boundary conditions $\mathrm{dT}(\theta)$ issolvedfirst, thenp $(\theta)$.

Boundary Conditions. Heat transfer from wall to gas is described as:

$$
\frac{\mathrm{dQ}}{\mathrm{d} \theta}=\frac{1}{\omega} \alpha(\theta)\left\{\left[\overline{\mathrm{T}}_{3}(\theta)-\mathrm{T}(\theta)\right] \mathrm{A}_{3}(\theta)+\left[\overline{\mathrm{T}}_{\mathrm{N}}-\mathrm{T}(\theta)\right] \mathrm{A}_{\mathrm{N}}+\left[\overline{\mathrm{T}}_{\mathrm{K}}-\mathrm{T}(\theta)\right] \mathrm{A}_{\mathrm{K}}\right\}
$$

$\omega$ - crank angular velocity; $\alpha(\theta)$ - heat exchange coefficient $\overline{\mathrm{T}}_{3}$ - cylinder face average temperature $\sqsubset$ 
$\overline{\mathrm{T}}_{\mathrm{N}}$ - piston face average temperature $\overline{\mathrm{T}}_{\mathrm{K}}$ - cylinder head face average temperature $\square \mathrm{T}$ - gas transient temperature $\square \mathrm{A}_{3} \square \mathrm{A}_{\mathrm{N}} \square \mathrm{A}_{\mathrm{K}}$ - area of cylinder face, piston face and cylinder head face;

$\alpha(\theta)$ is given as below[2]:

$\alpha(\theta)=0.053\left[\frac{\mathrm{D}_{\mathrm{e}}(\theta)\left[\frac{\mathrm{D}_{\mathrm{e}}(\theta)}{2} \omega_{\mathrm{g}}(\theta)\right]}{\mathrm{v}(\theta) \mu(\theta)}\right]^{0.8}\left[\frac{\mathrm{C}_{\mathrm{p}}(\theta) \mu(\theta)}{\lambda(\theta)}\right]^{0.6}$

$\mathrm{D}_{\mathrm{e}}(\theta)$ - equivalent diameter; $\omega_{\mathrm{g}}(\theta)$ - characteristic velocity; $\mathrm{v}(\theta)$ - transient specific volume $\sqsubset$

$\mu(\theta)$ - gas dynamic viscosity; $C_{p}(\theta)$ - gas specific heat capacity; $\lambda(\theta)$ - gas heat transfer coefficient; Reference to physical parameter diagram of dry air[3], fitting with Matlab:

$\mu(\theta)=655.3 \times \frac{(\mathrm{T} / 273)^{1.5}}{\mathrm{~T}+110}$

$\lambda(\theta)=-0.001515+0.000112 \mathrm{~T}-6.777 \times 10^{-8} \mathrm{~T}^{2}-2.485 \times 10^{-11} \mathrm{~T}^{3}$

$\mathrm{C}_{\mathrm{p}}(\theta)=1052-0.381 \mathrm{~T}+8.738 \times 10^{-4} \mathrm{~T}^{2}-4.048 \times 10^{-7} \mathrm{~T}^{3}$

Transient working volume is:

$\frac{\mathrm{dV}}{\mathrm{d} \theta}=\frac{\mathrm{S}}{2} \mathrm{~A}_{\mathrm{p}}\left[\sin \theta+\frac{\lambda \sin \theta \cos \theta}{\sqrt{1-\lambda^{2} \sin ^{2} \theta}}\right]$

$\mathrm{S}-$ piston stroke $\square \mathrm{A}_{\mathrm{p}}$ - piston head face area;

IIZA-1.5/8 compressor main parameter[4] listed as following:

Table 1 Main parameter of IIZA-1.5/8 compressor

\begin{tabular}{ccc}
\hline Crank angular velocity $\mathrm{n}(\mathrm{r} / \mathrm{min})$ & Piston stroke $\mathrm{S}(\mathrm{m})$ & Cylinder inner diameter $\mathrm{D}(\mathrm{m})$ \\
\hline $500 \mathrm{r} / \mathrm{min}$ & $0.114 \mathrm{~m}$ & $0.100 \mathrm{~m}$ \\
\hline
\end{tabular}

\section{Model Solving and Result Analysis}

Working parameter of compressor is: crank angular velocity $500 \mathrm{r} / \mathrm{min}$; intake air pressure $0.1 \mathrm{Mpa}$; intake air temperature 288K; discharge pressure 0.6Mpa.Case 1 and Case 2 respectively represent the situation of clearance volume $\mathrm{V}_{0}=20000 \mathrm{~mm}^{3}$ and $\mathrm{V}_{0}=80000 \mathrm{~mm}^{3}$.

Pressure Change in Cylinder.
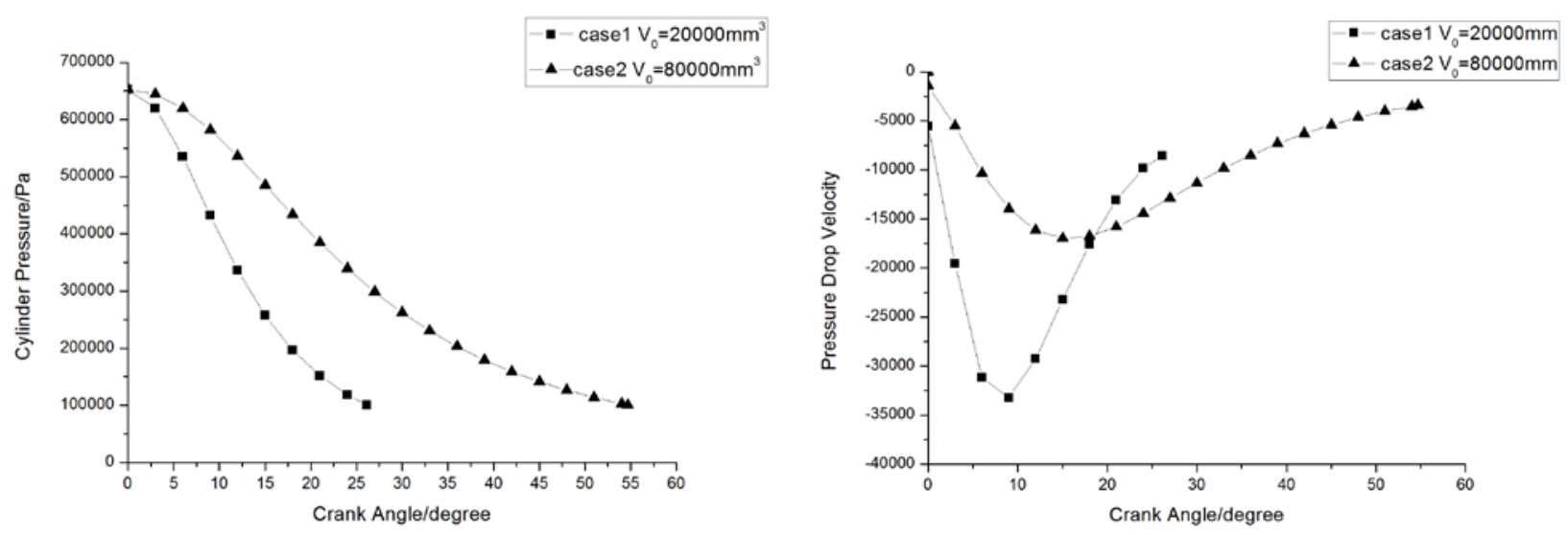

Fig.1 Pressure change in cylinder Fig.2 Pressure drop velocity

From Fig.1, when clearance $\mathrm{V}_{0}$ increase from $20000 \mathrm{~mm}^{3}$ to $80000 \mathrm{~mm}^{3}$, namelyFrom Fig.1,when 
clearance $\mathrm{V}_{0}$ increase from $20000 \mathrm{~mm}^{3}$ to $80000 \mathrm{~mm}^{3}$, namely relative clearance volume increases from $2.5 \%$ to $9 \%$ (360\% increased). Accordingly, expansion ending crank angle increases from $26^{\circ}$ to $55^{\circ}(202 \%$ increased). This is because clearance volume increasing result in expansion time increasing, therefore, temperature in cylinder dropping more heavily and gas specific volume decreasing. Thus, increasement of expansion ending angle is not proportional to the increasement of clearance volume. From Fig.2, trend of pressure dropping velocity of this two situation is same. They are all dropping fast and then slowing down.

\section{Gas Temperature Change in Cylinder.}
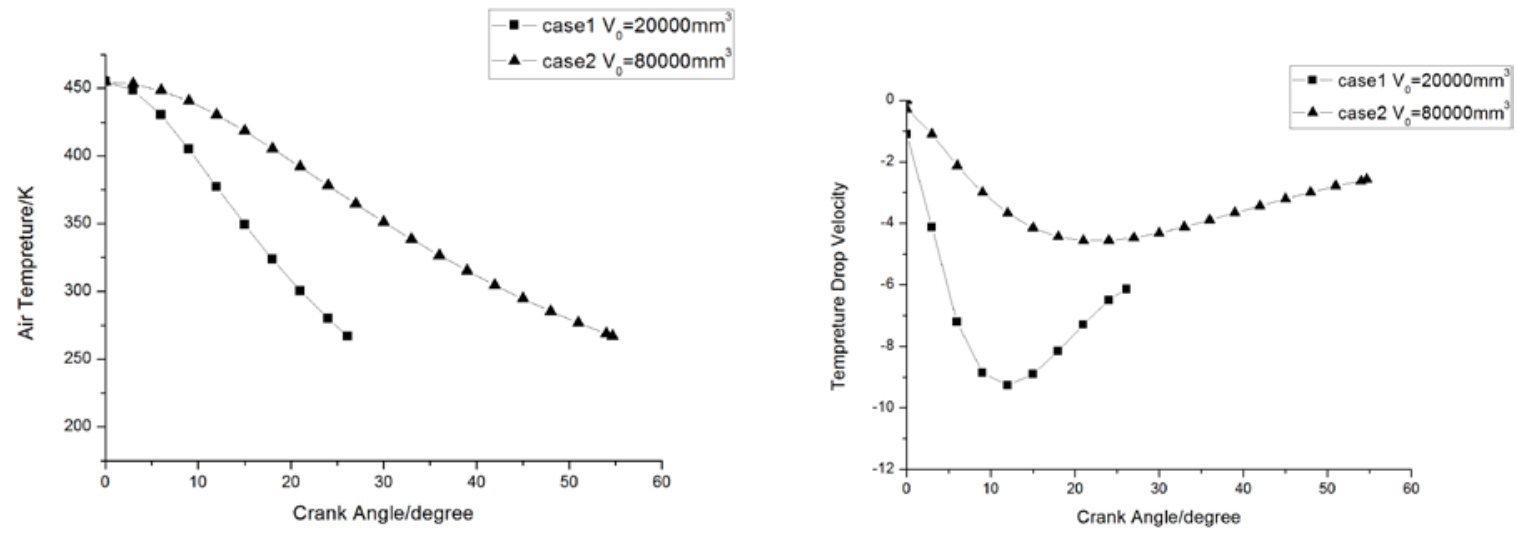

Fig.3 Pressure change in cylinder

Fig.4 Velocity of pressure change

From Fig.3,when clearance $V_{0}$ increases from $20000 \mathrm{~mm}^{3}$ to $80000 \mathrm{~mm}^{3}$,expansion ending temperature is all 266K.From Fig.4, when clearance $V_{0}$ increases from $20000 \mathrm{~mm}^{3}$ to $80000 \mathrm{~mm}^{3}$, velocity of temperature dropping is becoming faster obviously, and the velocity of case 2 is always smaller than of case1. This because the extension of expansion time makes more heat transfer from cylinder wall to gas, then the velocity of temperature dropping slows down.

\section{Model Visual Packing}
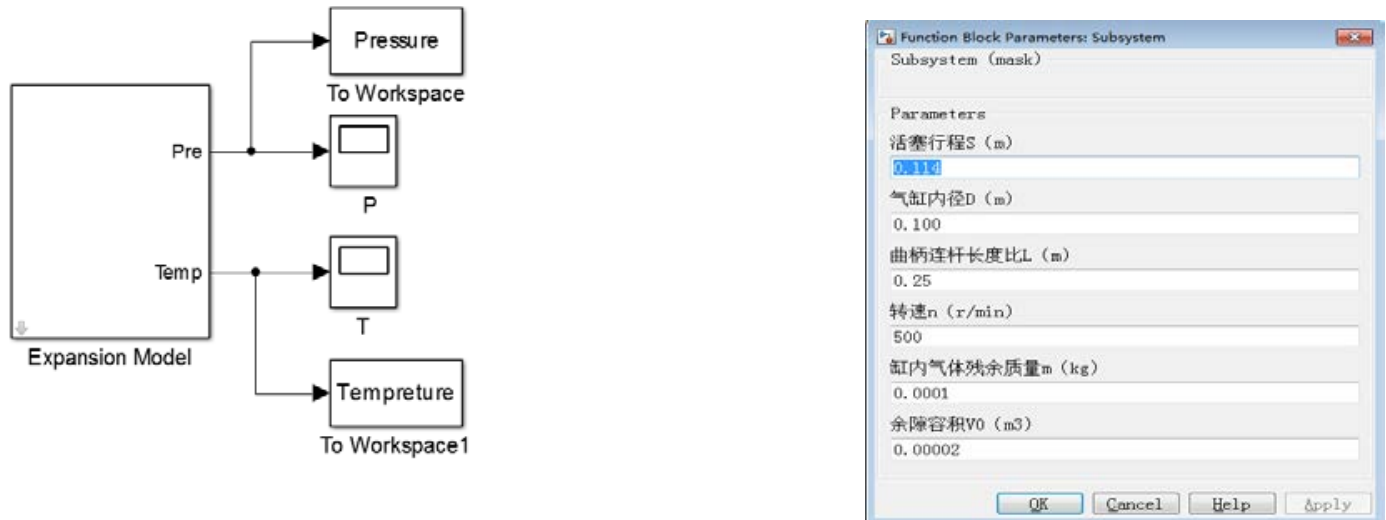

Fig.5 Simulink expansion model Fig.6 Parameter dialog box

Packing the Simulink model (shown in Fig.5), this model has 3 subsystem (inside the expansion model block).After being packaged, a dialog box will show once double-clicking, shown in Fig.6.Thus this model has strong visibility and easily to change concerned parameter to get the influence of other parameter on the system.

\section{Conclusion}

This reciprocating compressor expansion math model and simulink model is correct. It can reflect the expansion process well. Analyzing the math model with simulink can predict the clearance's influence on pressure and temperature. The surface of the simulink model is sample and easy to modify and can be used as a revising tool for reciprocating compressor design. 


\section{References}

[1] The Mathworks Inc, Using Simulink version 4, Using Simulink Version, 2000.

[2] Yongzhang Yu, Reciprocating compressor, first ed., China machine press,Beijing,1982.

[3] Shiming Yang, Wenquan Tao, Heat transfer, forth ed., High education press,Beijing,2006.

[4] Siying Sun, Tingrong Ren. New method of thermodynamic computation for a reciprocating compressors.Int, J. Mech. Sci,1995,37: 4. 